SAND79-1519

Unlimited Release uC -70

\section{MASTER}

\title{
LABORATORY STUDIES OF WATER TRANSPORT IN ROCK SALT
}

$J, J$, HOHLFELDER AND G, R, HADLEY

\section{s}


SAND79-1519

Unlimited Release

$\mathrm{UC}-70$

LAEORATORY STUDIES OF WATER

TRANSPORT IN ROCK SALT

J. J, Hohlfelder

Experiments Plannir:g Division

G. R. Hadley

Fluid Mechanics and Heat mansfer Division I

Sandia Laboratories

Albuquerque, NM 97185

November 1979

\section{ABSTRAC}

The trassport of water through rock salt as a result of heating is examines experimentaliy and a new nodel proposed to explain the data. The experixent consists of the measurement of water loss rate as a furction of time for three $\therefore \mathrm{kg}$ blocks of Southeasters New Mexico rock salt. Eacki block was heateci sor approximately three days with naximum temperatures ranging from $165^{\circ} \mathrm{C}$ to $250^{\circ} \mathrm{C}$. The resulting data is qualitatively explained by a continuur. model of Darcian flow of water vapor from a receding evaporation front. The model includez the prediction of thermal stresses which are calculated to crack the specimens during heater shutdown giving an anomalously high water loss spike in agreement with the data.

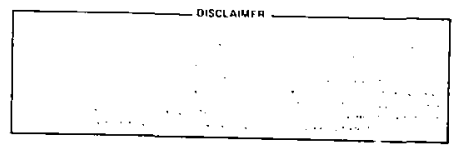




\section{ACKNOWLEDGEMENT}

The authors acknowledge the assistance of $R$. Villegas in performing the experiment and $R$. K. Thomas for writing the thermal stress subroutine. 


\section{CONTENTS}

Page

NOMENCLATURE

INTRODUCTION

EXPERIMENTAL SETUP

EXPERIMENTAL RESULTS

THEORETICAL MODEL

COMPARISON WITH EXPERIMENTS

DISCUSSION AND CONCLUSIONS

\section{FIGURES}

PIGURE I. Assembly: Heated Salt Specimen Apparatus

FIGURE 2, Water Loss rate for Heated salt Specimen

FIGURE 3. Schematic: Theoretical Model 
NOMENCLATURE

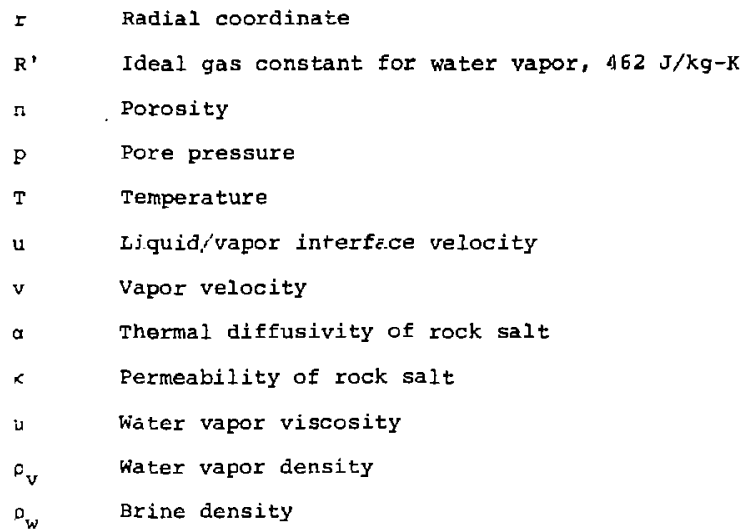




\section{INTRODUCTION}

Rock salt is presently regarded as one of the most promising geologic media for the disposal of high-level radioactive waste. Listed among its advantages is the absence of aquifers which might, if they were present, transport radionuclides away from the storage area. Some trapped water is present, however, in the form of brine inclusions, water of hydration, etc., and the movement of such water under the action of an imposed heat source (such as a waste canister) is fresently a subject of great interest.

The slow movement of brine through rock salt was first noticed about a decade ago in connection with waste disposal demonstrations tests. ${ }^{l}$ It was then described as being the migration of small ( I mm) inclusions through the $\mathrm{NaCl}$ lattice. ${ }^{2}$ This idea has since become the subject of intense investigation, both experimentally and theoretically. Inclusion migration is a well-known and complex phenomenon about which a sizable literature has developed. $3-7$

Here we report the quantitative measurement in the laboratory of the water loss rate of $1 \mathrm{~kg}$ heated rock salt samples over a period of three days. The results suggest that a different mechanism is in operation than was previously assumed, and that brine movement may be better explained as a Darcian flow of water vapor through a porous merlium. Frequently, this kind of mcdel has been applied in the theory of drying. ${ }^{8}$ Calculations using this model are plesented herein and compared with the data.

EXPERIMENTAL SETUP

A series of three tests was conducted in which $1 \mathrm{~kg}$ pieces of geologic salt were heated to temperatures up to $260^{\circ} \mathrm{C}$. Water loss from these specimens upon heating was determined: 
(1) by measuring the specimen's mass loss;

(2) by measuring the mass increase of a desiccant material placed in a gas flow stream which had pessed over the feated salt; and

(3) by integrating the time rate of water introduced into the gas flow stream. This rate was measured using commercially available dew point hygrometers, absolute pressure gages, and mass flow rate gages.

Each salt specimen was a $5.0 \mathrm{~cm}$ high by $10.8 \mathrm{~cm}$ diameter cylinder weighing approximately $1 \mathrm{~kg}$. The specimens were machined from salt biocks mined by the Mississippi Chemical Company from their mine located about 29 km East of Carlsbad, New Mexico. The blocks were removed from ore zone 7, approximately 210 metres below the surface in the MoNutt Potash zone, Salado Formation. The Inajor mineralogical constituents of the rock salt are approximately 88 o halite, 58 kainite, 48 polyhalite, and 38 sylvite. Prior to heating, the specimens were exposed to a laboratory air environment for up to one year after mining; their water content and permeability may differ from that of in situ salt. Each specimen was weighed and then placed into a thermally insulated gas-tight stainless steel enclosure as shown in section in Figure 1.

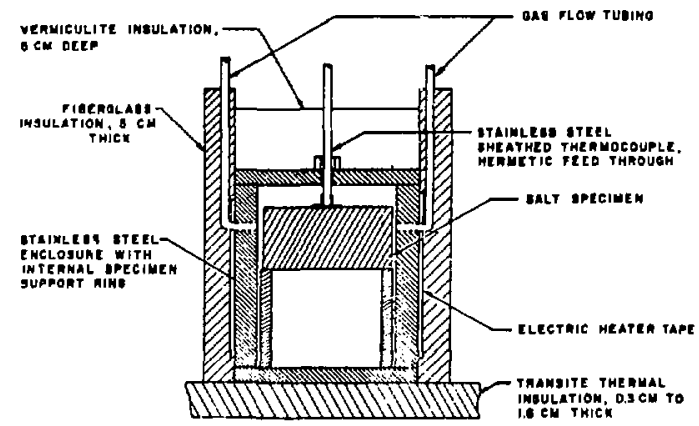

FIGURE 1. As;embly: Heated Salt Specimen Apparatus 
The sample was heated using electrical heater tape wrapped around the circumference of the enclosure. The temperature of the salt was measured using a therrocouple in contact with the specimen's top surface. Each specimen was heated sequentially at the two input power levels of $67 \mathrm{~W}$ and $116 \mathrm{~W}$ for a total duration of about 80 hours. During working hours, a continuous record of sater loss rates was determined by the dew point hygrometers to an estimated accuracy of \pm 8 . At the end of each run, after the sample had cooled to room temperature, both the sample and the desiccant material were reweighed, giving a total mass loss and mass gain, respectively. For rach run, the latter two were fould to agree with each other to within $10 z$ and to agree with the time integral of the mass loss rate to within $20 z$.

\section{EXPERIMENTAL RESULTS}

The results of tije three heated salt water analyses are sumarized in Table I. The third specimen lost more water than the first two because it was raised to a higher maximum temperature. A typical water loss rate curve (i.e., the data for sample 2) is shown in Figure 2. Characteristics of this water loss rate curve common to all three samples are: the monotonically declining rate after the sample is placed in the enclosure at room temperature, and the increase in the rate following an increase in the heater power with the attainment of a maximum followed by a slow, monotonic decrease. Finally, an abrupt increase in water loss rate upon the removal of heater power was measured for two of the specimens. (This may have occurred during the first specimen's run, but the dew point gages were not monitored after the power was turned off.) The water released during this sudder outflow is from 5-108 of the total water released by the salt. This sudden relezse is similar to phenomena observed during measurements made $i$ ? heated geologic salt during project salt vault. ${ }^{1}$ 


\begin{tabular}{|c|c|c|c|}
\hline \multirow[b]{2}{*}{ Measured Mass Change } & \multicolumn{3}{|c|}{$\begin{array}{l}\text { ThiLE I } \\
\text { Heated Salt Specimens } \\
\text { Mass Change - gm } \\
\text { Salt Specimen Number }\end{array}$} \\
\hline & 1 & 2 & 3 \\
\hline Mass Loss Upon Heating & $\begin{aligned} 1.26 & +.06 \\
& -.03\end{aligned}$ & $\begin{aligned} 0.98 & +.06 \\
& \cdot .03\end{aligned}$ & $\begin{aligned} 1.47 & +.06 \\
& -.03\end{aligned}$ \\
\hline $\begin{array}{l}\text { Time Integral of Net } \\
\text { Water Loss Rate }\end{array}$ & $1.38 \pm .11$ & $0.96 \pm .08$ & $1.85 \pm .15$ \\
\hline $\begin{array}{l}\text { Mass Gain of Desiccant } \\
\text { Cartridges }\end{array}$ & $1.14 \pm .05$ & $0.98 \pm .05$ & $1.32 \pm .05$ \\
\hline $\begin{array}{l}\text { Average } \pm \text { RMS } \\
\text { Mass Loss in Postheating } \\
\text { Pulse (200 Minute } \\
\text { Intervil), Percent of } \\
\text { Total }\end{array}$ & $1.26 \pm .12$ & $\begin{array}{l}0.97 \pm .01 \\
0.097 \\
9.0\end{array}$ & $\begin{array}{l}1.55 \pm .27 \\
0.112 \\
5.5\end{array}$ \\
\hline
\end{tabular}

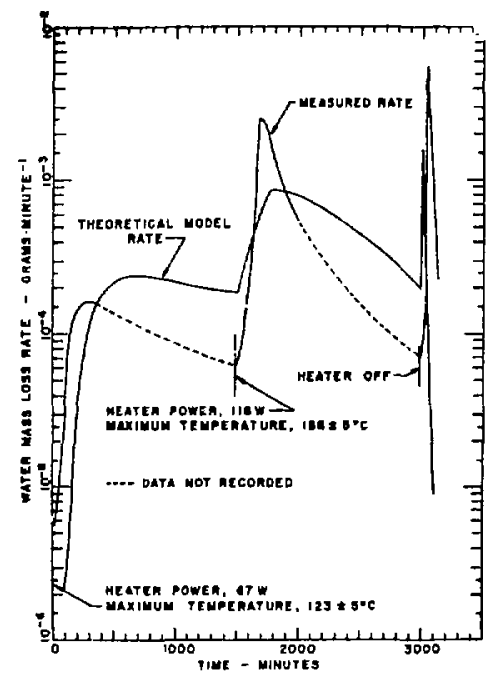

FIGURE 2. Water Loss Rate for Heated Salt Specimen 
THEORETICAL MODEL

The model used to simulate the experiments described above incorporates the following assumptions and simplifications:

(1) The cylindrical salt block was modeled in one dimension by a sphere with volume equal to that of the cylinder. Sperical symetry is assumed for all variables.

(2) Water motion within the salt is assumed to be a Darcian flow of water vapor from a receding evaporation front.

13) The permeability of the salt is taken as a constant except where radial cracks are predicted, in which case it is increased by a factor of 40 . Both cracked and uncracked permeabilities are chosen to fit the data presented here.

(4) The porosity is estimated from the total water loss to be $\sim 0.0025$.

(5) All vapor motion proceeds on a time scale which is short compared to other characteristic times and consequently remains in a steady state.

A schematic diagram of the model is shown in Figure 3 . In region $I$, there is vapor only wich obeys the steady state continlity equation

$$
\frac{\partial}{\partial r}\left(r^{2} \rho_{v} v\right)=0
$$

and the ideal gas equation of state

$$
p=R^{\prime} p_{v}^{T}
$$

Vapor velocities are computed from Darcy's Law

$$
\mathbf{v}=-\frac{\kappa}{\mu} \frac{\partial p}{\partial r}
$$

All pore pressures are considered to be partial pressures of water vapor with boundary conditions $p=0$ at the outer radius of the salt and $p=$ equilibrium 
vapor pressure at the evaporation front. The effect of disolved solids on the vapor pressure has not been included but should be less than a factor of 2 below $200^{\circ} \mathrm{C}$. The evaporation frost recedes at the rate

$$
u=-\frac{\rho_{v}^{v}}{\rho_{w}} .
$$

The temperature is found from the time-dependent heat conduction equation

$$
\frac{\partial T}{\partial t}=\frac{a}{r^{2}} \frac{\partial}{\partial r} r^{2} \frac{\partial T}{\partial r}
$$

Here, the outer boundary condition consists of experimentally measured tenperatures.

In addition, we compute the stresses in the salt, arising from both therinal gradients and pore pressure, using a self-consistent technique which allows for cracking. Whenever a principal tensile stress exceeds a preset tensile strength, the str:sz is artificially reduced to zero. The entire calculation is then redone and the process continued until a self-consistent solution is obtained.

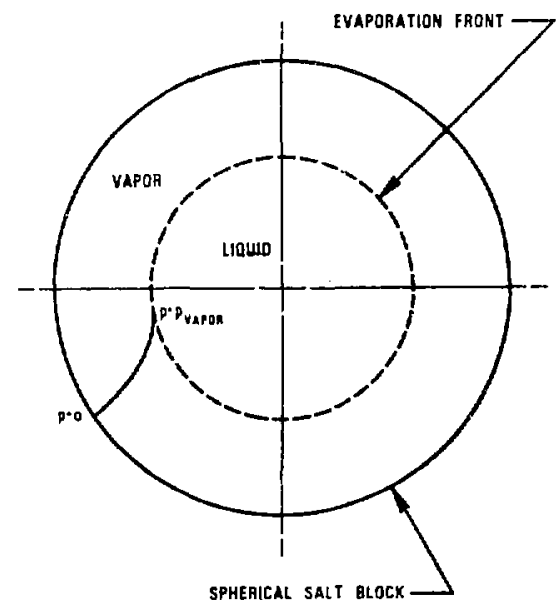

FIGURE 3. Schematic: Theoretical Model 
COMPARISON WITH EXPERTMENTS

Equations (1) through (5) plus the equations for thermal stress-strain were solved using the measured temperatires for sample 2 as input. The predicted water loss rate is shown in Figure 2. The broad peaks during heatup represent the competition between rising temperature and receding evaporation front. During heatup, all tensile stresses were p:-edicted to remain well below known tensile strengths for rock sát. ( 1.2 to $1.7 \mathrm{MFa}) .^{9}$ During couldown, however, cracking is predicted which leads to the sharp peak in water loss rate shown. The base value of permeability used in this simulation which gave the best fit was $0.04 \mu \mathrm{D}\left(4 \times 10^{-16} \mathrm{~cm}^{2}\right)$. For mineralogically similar salt, values of permeability measured with the si $: t$ specimen under various confining stresses vary from 8 HD to $0.05 \mu \mathrm{D} .10$

\section{DISCUSSION AND CONCLUSIONS}

The model described above, although in need of refinement, is clearly capable of reproducing the esgential features of the data, including the sudden release of water when power is turned off. The previously heid inclusion migration model appears to be inadequate in at least two respects:

(1) There are long periods of time ( 4 hours) during which predicted temperature gradienta $\left(0.05^{\circ} \mathrm{C} / \mathrm{cm}\right)$ are over an order of magnitude below threshald gradients for incluaion migration, ${ }^{6}$ though the data shows no dramatic decrease in water loss rate.

(2) Slow velocities of inclusion movement $\left(10^{-7} \mathrm{~cm} / \mathrm{s}\right)$ appear to be inadequate to explain the sharp spike that occurg when power is eurned off.

Experiments conducted on larger $(-1 \mathrm{~m}$ ) salt blocks are presently in progress uging a somewhat different geouetry and more elaborate data gathering techniques. Also, refinements in the theory are proceeding toward a more exact two-phase 
flow model which, hopefully, will result in a better comparison with experiment. The purpose of the oresent paper is to demonstrate the approximate validity of a new approach to water transport using laboratory data. 


\section{REFERENCES}

1. W. J. Boogly, Jr., R. I. Bradahaw, F. M. Empoon, W. F. Schaffer, Jr., F. L. Parker, and J. O. Blane:ske, Health PhygicB, 12, 417 (1966).

2. R. I. Bradshaw and F. Sanchez, Journal of Geophysicel Research, 74, 4209 (1969).

3. P. Hoekgira, T. E. Osterkamp, and W. F. Weeks, Journal of Geophysical Regearch, 70, 5035 (1955).

4. H. E. Cline and T. R. Anthony, Acta Matallurgica, 19, 175 (1971).

5. T. R. Anthory and H. E. Eline, Fourth International Symposium on Salt-Northern Ohio Geological Society, 313 (1974).

6. T. R. Anthony and H. E. Cline, Jourral Agplied Physics, 43, 10 (1972).

7. T. R. Anthony and H. E. cline, Acta Metallurgica, 19, 491 (1971).

8. M. D. Mikhailov, Int. Journal Heat and Mass Trangfer, 18, 797 (1975).

9. F. D. Hansen ana P. F. Gnirk, RE-SPEC, InC., Report RSI-0029, Rapid City, South Datota (1975).

10. H. J. Sutherland and S. Cave, SAND78-2287, Sandia Laboratories, Albuquerque, New Mexico (1979). 